\title{
Increasing Speaking Skill through YouTube Video as English Learning Material during Online Learning in Pandemic Covid-19
}

\author{
Ahmad Nur Syafiq, Amalia Rahmawati, Anwari, and Tyas Oktaviana \\ Universitas Muhammadiyah Kudus, Kudus, Indonesia \\ ahmadnursyafiq@umkudus.ac.id
}

\section{ARTICLE HISTORY \\ Received : 19 February 2021 \\ Revised : 20 February 2021 \\ Accepted : 26 February 2021}

\section{KEYWORDS}

YouTube Video

Speaking Skill

Online Learning

\begin{abstract}
YouTube video is one alternative solution in teaching speaking during pandemic. This study attempts to find the use of YouTube videos to improve speaking skill of students and how teaching and learning process using YouTube videos are implemented in the class. A classroom action research was conducted to first semester college students of Muhammadiyah University of Kudus in 2020. The population of this study was all nonEnglish program and the samples were 85 students in redundant class chosen using purposive sampling. The data were obtained from speaking assessment and interview and later analyzed by using constant comparative method and descriptive statistic. This study showed that YouTube video as English learning material improved speaking skill of students including fluency, vocabulary, pronunciation, grammar, and content. Therefore, it can be concluded that the use of YouTube Video is able to improve the students' speaking skill during online learning in pandemic Covid-19. Further study may concern on the use of YouTube Video to teach other English skills like reading and writing.
\end{abstract}

\section{Introduction}

The spread out of the novel coronavirus (Covid-19) affects to the educational system in our country (Indonesia). Moreover, Ministry of Education and Culture, the government issued a policy package, which is distance learning for all levels of education (Abidah et al., 2020). Online teaching system is the alternative solution to teach English especially speaking skill.

Spoken language is extremely different from written one in the way that it deals with vocabulary, pronunciation, grammar and fluency. In fact, students have problems communicating actively and spontaneously in English even though they have sufficient vocabulary to express their ideas and feelings, they still do not know how to say them. Moreover, students say speaking is more difficult than reading, writing or listening for two reasons. First, speaking is valid in the real world. Usually that person, with whom we are chatting, is waiting for us to chat at that time. Second, when we speak, we cannot edit and revise what we want to say, as we can do in writing.

Some of the problems in the teaching and learning process in the language class are: 1) Some students are afraid to make mistakes in front of their classmates. 2) A number of students kept asking their friends about English vocabulary to make verses. 3) Students face difficulties to express their opinion orally. 4) Students need a long time to compose and recite a verse. 5) Some students are not sure what they are talking about. The bragging findings concluded that other problems in English language proficiency were grammar, fluency, and pronunciation.
Sayuri (2016) had encountered these problems. In his investigation, students face problems in English dealing pronunciation, fluency, grammar, and vocabulary. Students also show other problems that are obtained than students' personal information, namely lack of self-confidence, fear of making mistakes, embarrassment of others, nervousness, staying in English, never practicing, and there is nothing to say (Sayuri, 2016). The same case argues that students have problems expressing themselves in speaking because they are reluctant, hesitant, and afraid of making mistakes, lack of sufficient vocabulary, and lack of practice that makes students find it difficult to pronounce sounds in English fluently. The students appeared somewhat and were reluctant to speak because they had nothing to say. Even though they have something in mind, they are prevented by being unsure because they are afraid of making mistakes in grammar and they hesitate if other students laugh at them when they make mistakes (Meinawati et al., 2020).

Following the objectives and conditions mentioned above, it is very urgent and necessary for the speech class teacher to make every effort to turn some of these situations into positive states. Therefore, from the needs of teaching, YouTube can be used as a strategy in teaching speech. YouTube was chosen because this web page contributes a lot to the teaching and learning process. It provides a lot of video content which can be utilized for classroom use. YouTube as a medium is used by teachers to solve this problem in the first step. Khalid (2012) defined YouTube as a video partnership web page where users can upload, share and view videos (Riswandi, 2016). According to Burke (2009) YouTube is a public access Web-based platform that allows people to easily upload, view, and share video clips 
via the internet via www.YouTube.com, other web pages, mobile devices, blogs, and email (Burke \& Snyder, 2008).

The education system in our country had to adapt to the situation during pandemic in the way that teaching usually done face-to-face was changed to online teaching. There are many techniques for teaching speaking, both in offline teaching and in online teaching during pandemic (Tristiana1 \& P. Swondo, 2020). Distance learning causes many problems, such as miscommunication between teacher and students (Abidah et al., 2020). Distance learning is learning without face to face, distance learning can use applications in the form of YouTube, Facebook, WhatsApp, Twitter, etc. there are so many advantages of distance learning, one of which is very convenient, tests could be passed any time, and in any place, it helps to improve the knowledge of English,

Nafisah (2017) conducted a study to determine the effect of computer-assisted language learning (CALL) on students' achievement. The result was that students who used CALL got higher scores. The study proved that there was a positive effect in using online media on students' achievement (Al-Nafisah \& Al-Domi, 2017). Moreover, Rizki (2020) did a research to find out students' perspectives on online tools it called quiz let, online websites on speaking development of Turkish EFL learners. The results of this study were that some students felt motivated. Students said that activities using online tools were fun and enjoyable, but some students also felt difficult since online tools cannot provide enough examples for students to learn (Rizky Setiawan \& Wiedarti, 2020).

YouTube is considered as an alternative strategy for improving student-speaking proficiency. After watching videos based on YouTube, it is hoped that students can get ideas for speaking from the real environment of speakers so that students have the opportunity to make speech offerings that are imitating, intensive, responsive, intensive, interactive and broad. Students can also get new vocabulary words and examples of pronunciation which give them the opportunity to make improvements. Speaking proficiency would be better if it was supported by the actual environment or valid material as a student scheme (Wael Abdulrahaman, 2016). The implementation of this strategy includes the phases based on the prior task, the task cycle, and the focus language phases. This strategy is expected to help students solve problems and improve student pronunciation achievement.

YouTube belongs to online resource, which is very important in the teaching and learning field. This webpage can provide students with daily videos of valid situations that can help them improve their understanding and achievement in English lessons (Riswandi, 2016). As many investigators have noted, students can get positive cues when they watch clips that are valid and real (Anwar et al., 2017). Using YouTube videos to teach English classes as additional material will give students a good understanding and knowledge of their course. On the other hand, it may make the learning process more harmonious and meaningful. In addition, it gives students the opportunity to memorize their lessons more easily.

Based on the observations in the first grade of nonEnglish study program in the academic year of 2019-2020 when the author taught in the classroom, there are many reasons that students do not speak. This is because learner's shyness or lack of confidence to speak English. In the preview, their study of English was not optimal. They do not use English in their daily life even though they are grateful and meet. Sometimes students do not pay attention while they are studying in the classroom. They are sleepy, do not really understand the material but are embarrassed to ask the teacher, and do not usually use a dictionary. They consider that learning English is difficult and not their daily language, so their studies of English are not interested.

Furthermore, COVID-19 deeply affected the state of English teaching and learning in which the class is not able to be done by face-to-face learning or they must conduct virtual learning by using online applications. This condition of course has impact on university students to learn English therefore this study aims to examine the use of YouTube videos to improve students' speaking skill and how the teaching and learning process using YouTube videos is carried out in the classroom during pandemic covid-19.

\section{Literature Review}

\subsection{Speaking}

Speaking is one of four language skills in which for many students learning to speak fluently in English is a priority. It is because they use speaking skill to keep up rapport in relationship, influence people, and win or lose negotiations as parts of communication (Breene, 2012). There are some methods that can be used to develop students' speaking ability. Planning, rehearsal, repetition are some of the methods which play important role in related to enhancing speaking skill (Harmer, 2011). Related to give the clear description about how to improve the students' speaking skill, it is also important to discuss the type of skills in speaking. According to Brown (2004), there are some differences of micro skills and macro skills of speaking. The micro skills are skills related to production of the smaller chunks of language units such as phonemes, morphemes, words, collocations, and phrasal units. On the other hand, the macro skills are skills related to the mastery on the larger elements of language units, for examples, fluency, discourse, function, style, cohesion, nonverbal communication, and strategic options.

\subsection{Assessing Speaking}

Thornburry (2005) claims that there are two main ways to assess speaking. They are holistic scoring and analytic scoring. Holistic scoring uses a single score as the basis of an overall impression, while analytic scoring uses a 
separate score for different aspect of the task. Each of those has its own advantages where holistic way is quick and suitable for informally assessing progress. Meanwhile, analytic scoring takes longer since it requires the teacher to take a variety of factors into account and is probably fairer and more reliable. This study employs analytic system based on Pandiya (2013) which is divided into six components to be assessed such as fluency, grammatical accuracy, pronunciation of sentences, pronunciation of words and sounds, interactive communication, and vocabulary resources.

\subsection{YouTube}

Internet is media supporting the educational process and has a big influence for student's achievement in the way that videos in the internet are very effective in the world of education (Apuke \& Iyendo, 2018). Moreover, teachers are able to use video as a means of teaching and learning in English class and it produces interactivity between students that supports social pedagogy (Wael Abdulrahaman, 2016). According to (Kabooha \& Elyas, 2018), YouTube is an internet medium that greatly contributes to education in general. Furthermore, it offers instant access to teaching, culture-based videos, and languages from around the world. YouTube Video plays vital role of language teaching in college classrooms (Fleck et al., 2014). YouTube videos are a relatively simple strategy for making teaching materials relevant and specific to learning English because it contains videos from great scientists, writers, TV news broadcasts, politicians, and other TV programs (Pratama et al., 2020).

\subsection{Online Learning}

Online learning is a teaching and learning process that utilizes an internet connection and learning platforms. Ade Kusuma in La Ode Anhusadar described that online learning is a learning process that utilizes an information technology, in this case utilizing the internet as a method of information delivery, interaction, and facilitation. On the other hand, Adijaya \& Lestanto also explained that online learning can be done in an easy way because it only relies on applications that are connected to the internet (Swari, 2020). To continue the learning process during this pandemic, many online platforms that can be used, such as zoom, Goggle classroom, Goggle meet, Moodle, etc. The online platforms promote both inquiry based learning and independent learning since the online platforms facilitate interactions between teacher and students although they are not in the same room (Nartiningrum, n.d.2019).

\section{Method}

This study employed an action research. The use action research in this study was to see how YouTube video improve students' speaking skill during online learning in the pandemic covid-19. This action study began with observation in which researcher discussed the problem in the English speaking classroom during online learning due to pandemic covid-19 and chose YouTube Video as the
English speaking material. Later, researcher implemented YouTube Vides as material in teaching speaking class observed the students'activities while teaching and learning process occur. The result of the observation was recorded. Furthermore, after carrying out the teaching process, the researcher recites the occurrence in classroom as the reflection of the action. The researcher evaluates the process and the result of the implementation of YouTube video in English teaching.

The population were first grades of all students of nonEnglish program of Universitas Muhammadiyah Kudus in the academic year of 2019-2020 including 205 students meanwhile the total samples were 85 students taken by purposive sampling because researcher had access to teach those samples. To collect the data, this study used some instruments including observation, which provide total concern to research object of the sense, which aims to explain the situation in class activities, individual involvement in some activities and the relation between situation, activity and individual. Documentation is done to get information explicitly and test which is in the form multiple-choice question. After data were collected, they were later analyzed into qualitative and quantitative analysis to explain the result of observation and test.

\section{Results}

To include excerpts or quotations from literature, make the transcripts in font size 9 and the code or label aligned to the right. Based on the result in every cycle, the use of YouTube video had increased speaking skill of aspect even though it is not quite significant. The average score of all speaking aspects in every cycle can be seen in the following table.

Table 3.1 Average score of all speaking indicators

\begin{tabular}{lrrrrrr}
\hline \multicolumn{7}{c}{ Average score of all speaking indicators } \\
\hline Test & $\begin{array}{r}\text { Fluency } \\
(1-20)\end{array}$ & $\begin{array}{l}\text { Vocab } \\
(1-20)\end{array}$ & \multicolumn{1}{l}{$\begin{array}{l}\text { Pronun } \\
(1-20)\end{array}$} & $\begin{array}{l}\text { Gram } \\
(1-20)\end{array}$ & $\begin{array}{l}\text { Content } \\
(1-20)\end{array}$ & Total \\
\hline Pre & 10.3 & 11.7 & 11.4 & 12.1 & 13.3 & 58.8 \\
Post 1 & 13.2 & 12.8 & 12.7 & 14.2 & 14.6 & 67.5 \\
Post 2 & 15 & 16.2 & 15 & 16.3 & 16.2 & 78.7 \\
Post 3 & 17.3 & 18.1 & 17.4 & 18 & 19 & 89.8 \\
\hline
\end{tabular}

In the pretest, the average score of the students' speaking test was 58.8 from 85 students, while the maximum score was 68. Later on, the average score of speaking in Cycle 1 (posttest 1) was 67.5 from 85 students while the maximum score is 72 . The average score of speaking in cycle 2 (posttest 2) was 78.7 while the maximum score 82 and the average score of speaking in cycle 3 (posttest 3) was 89.8 while the maximum score 92 . Therefore, it can be said that based on the result of the speaking test, there was an increasing of students' speaking achievement. 


\subsection{Observation Results}

\subsubsection{Cycle One}

Cycle one ran for three meetings. In the pre-assignment phase, begin with a speech, check the student attendance list, and inform the learning objectives and assigned tasks. In addition, the proliferation of ideas and the activation of background and contextual knowledge are done before undergoing speech training. Several pictures and videos related to the lesson were used and students were asked to read words and sentences for speaking exercises as a warmup activity. In the task cycle, the activity is divided into three stages, namely tasks, planning and reporting.

In the first stage, students must be paired to watch YouTube videos and they are allowed to make notes. In the second stage, students create a script or text to have a conversation and in the last stage, then, they have a conversation in pairs in front of the class. Third, language focus, during this phase, all students provide comments or suggestions on their peers' performance. After students comment, it is the teacher's turn to provide feedback and comments. After the comments and suggestions given by students and teachers, it is time for teachers to make an assessment of today's teaching and learning.

Based on the results of the observations, most of the students observed the screen carefully. It was found that an average of $75 \%$ - $92 \%$ of students watched the video at the first, second and third meetings. These findings indicate that there is an increase in terms of motivation and interest of students in this speaking class. As they watched the video, students wrote the information obtained from the video on a worksheet. However, when they are on time to talk to their partner, the students seem to be still passive. Probably due to lack of vocabulary possessed by students. Searching for vocabulary in the dictionary is often done by students during discussions.

\subsubsection{Revision}

Cycle 1 proved activity of the learning and teaching using YouTube-based videos is great. However, it is still found that the students' speaking improvement was not so significant. Therefore, there were still some points which need to be improved by the teacher. Several points need to improve. First, the students in cycle two and three were set up in group $3-4$. Second, the YouTube-based videos used by the teacher itself. In cycle one, the teacher only showed the videos in offline mode and play them only twice in the task cycle phase. However, in the cycle two and three, the teacher asked students to bring minimum bring one laptop per group. The students then had chances to play the videos from YouTube in online mode and they can watch it for many time in the task cycle phase.

In addition, the revision in Cycle 2 and 3 also focused on how to help students enrich their vocabulary, improve their pronunciation and improve the students' idea by developing material, teaching instruction. This based on the result of students' speaking skills score in the cycle one which showed that their vocabulary, pronunciation, and content are still not so good. For enriching and improving vocabulary and pronunciation, in the pre-task phase, the new vocabulary with the meaning related to the topic was shown. In cycle two and three, the students also had a longer time for memorizing vocabulary and practicing pronunciation. The meaning of the words was also explained in the native language of the students (Bahasa Indonesia). To stimulate the students' idea, the worksheet was completed with more detailed questions related to the content of the video. The questions about the content of the video were also displayed on the video before the students watched it. Students in this cycle two and three had more time to watch YouTube-based video and they can find out the appropriate and similar videos on YouTube by themselves.

\subsubsection{Cycle 2 and 3}

The teaching method in cycles two and three are the same as in cycles one. A significant difference in this cycle to the previous one is the YouTube-based video game mode. In these cycle, students are allowed to watch videos in online mode and use their own devices. The number of groups also varies; they are in this cycle in groups $3-4$. Therefore, time allocation for student performance is also increased.

Like the first cycle, the results of activities in cycle two are also taken by teachers through observations, tests, questionnaires, and interviews as follows: first, based on the teacher's observations when the video is played, most students pay attention to the screen and video they watch. It was found that an average of $95 \%-100 \%$ of students watched the video at the first and second meetings. Classroom conditions are also more conducive as all students take the class seriously. These findings indicate that there is a significant increase in the motivation and interest of students in this speaking class compared to the initial study and first cycle. While watching the video, students write the information obtained from the video on a worksheet. Students seem to be more active when it comes time to discuss those materials with their peers.

\section{Discussion}

Based on the research results, YouTube as a teaching material can improve student achievement in learning English, especially speaking. This is in line with study conducted by (Meinawati et al., 2020) which stated that YouTube is effective to teach speaking class during pandemic Covid-19. In this case, YouTube videos are a combination of visual context with spoken language and develop students' ability to enjoy and understand English lessons so that students are more happy and motivated to learn English. Moreover, YouTube video was used effectively; it enhanced students' speaking skill, and classroom climate during online learning. In conclusion, YouTube video can be applied as an alternative media in 
language-teaching process include for teaching speaking (Wael Abdulrahaman, 2016). By using YouTube videos, students are able to remember lessons and make it easier for them to discuss topics that are studied about English material with their classmates and teachers actively so that YouTube makes students more creative and innovative in the field of learning English in virtual class.

Later on, using YouTube as learning material during pandemic also helps students improve their speaking skill and attract student's attention when learning in the way that students are more interesting in learning when the situation and condition in the class is different than usual thus It makes them enthusiast and feel more ease. YouTube was very effective because it allowed students to speak with more confidence and expression and they also did not have to worry about the phrases they used when speaking because they were able to see how foreigners speak English properly and correctly (Fleck et al., 2014).

Furthermore, YouTube videos as teaching material make students are more motivated and less bored in the class and can be used to study groups in doing assignments that make students more active in class during pandemic. The finding also states YouTube videos help students learn about speaking in terms of how to speak (fluency), vocabulary, pronunciation, grammar, and what content will be spoken is better where after learning from the video, students get ideas to speak and continue to discuss in groups so that each student has the opportunity to exchange information verbally with group members. This is in line with study conducted by (Ariyanto et al., 2018) which stated YouTube helps some students to speak actively in class and increase their motivation to speak

Based on the results of observations, it is stated that the successful of learning speaking is determined by several factors, including the appropriate learning materials and media. YouTube as an effective tool that can enhance the learning experience if the video is indeed relevant to the subject at hand (Meinawati et al., 2020). Students are more confident to speak English because using YouTube videos means students do not meet directly when speak English. This finding is supported by Tarigan's theory (2008) speaking is the ability of a person to express her knowledge, convey ideas of words, and convey thoughts in front of people. Most of the statements above indicate that using YouTube videos can make a sense of confidence to speak English.

Moreover, the use of YouTube videos can be used as an alternative to teaching speaking in English classes where the topics given in the form of YouTube videos make it easier for students to elaborate the understanding of the material and improve your speaking skills in class. Students also Feel Enjoyable Learning Interpersonal Speaking by Using YouTube Video. These findings are like the theory of herrman (2016), by using YouTube in teaching English can improve students' understanding and students' skill. In addition, YouTube can be an alternative learning clinical skills based on video, as a teaching tool to create an active and enjoyable.

\section{Conclusion}

It can be concluded that the application of YouTube videos in teaching English really improves students' speaking skills and motivation during online learning in the pandemic Covid-19, which can be seen from the results of speaking test development in each cycle. Moreover, the use of YouTube videos in learning speaking increases students' learning motivation in speaking class in the way that YouTube videos provide images and audio thus it can help students practice pronunciation, enrich their vocabulary and make it easier for them to find ideas in producing sentences while speaking. In addition, watching videos also subconsciously helps students learn grammar automatically.

Also, YouTube could be great material to teach speaking and it helps the students to understand the lesson as well during online learning. Therefore, the use of YouTube can be an effective method in dealing with students' difficulties and barriers in understanding English especially speaking along virtual class. Future study may concern on the use of YouTube videos in teaching other English skills during online learning in the pandemic covid19.

\section{Acknowledgement}

This research was supported/partially supported by Muhammadiyah University of Kudus, especially the Head of Research and Publication Department of UMKU for the assistance with the particulars of research technique, methodology. The authors also appreciate the reviewers for the comments that greatly improved the manuscript's quality.

\section{References}

Abidah, A., Hidaayatullaah, H. N., Simamora, R. M., Fehabutar, D., \& Mutakinati, L. (2020). The Impact of Covid-19 to Indonesian Education and Its Relation to the Philosophy of "Merdeka Belajar." Studies in Philosophy of Science and Education, 1(1), 38-49. https://doi.org/10.46627/sipose.v1i1.9

Al-Nafisah, K. I., \& Al-Domi, I. M. (2017). The Effects of Computerized Instructional Program on Saudi High School Students' Academic Achievement in English. SSRN Electronic Journal, 1, 506-520. https://doi.org/10.2139/ssrn.2804036

Apuke, O. D., \& Iyendo, T. O. (2018). University students' usage of the internet resources for research and learning: forms of access and perceptions of utility. Heliyon, 4(12), e01052. https://doi.org/10.1016/j.heliyon.2018.e01052

Ariyanto, N., Rochsantiningsih, D., \& Pudjobroto, H. (2018). Enhancing Students' Speaking Skill by Using 
Youtube Video. English Education, 6(3), 278. https://doi.org/10.20961/eed.v6i3.35883

Brown, H. Douglas. 2004. Teaching by Principles an Interactive Approach to Language Pedagogy. Longman.

Burke, S. C., \& Snyder, S. L. (2008). YouTube: An Innovative Learning Resource for College Health Education Courses An Overview of YouTube Using YouTube in Higher Education. International Electronic Journal of Health Education, 11, 39-46. http://eric.ed.gov/?id=EJ798652

Zakiyah Anwar et al (2016). Enhancing Students' Speaking Skill through Gallery Walk Technique Farrah. 253268.

Fleck, B. K. B., Beckman, L. M., Sterns, J. L., \& Hussey, H. D. (2014). YouTube in the Classroom: Helpful Tips and Student Perceptions. The Journal of Effective Teaching, 14(3), 21-37.

Handi Pratama, S. H., Ahsanul Arifin, R., \& Sri Widianingsih, A. W. (2020). The Use of YouTube as a Learning Tool in Teaching Listening Skill. International Journal of Global Operations Research, l(3), 123-129. https://doi.org/10.47194/ijgor.v1i3.56

Harmer, Jeremy. 2011. The Practice of English Language Teaching. Third edition. Longman Pearson Education Limited.

Kabooha, R., \& Elyas, T. (2018). The Effects of YouTube in Multimedia Instruction for Vocabulary Learning: Perceptions of EFL Students and Teachers. 11(2), 72-81. https://doi.org/10.5539/elt.v11n2p72

Meinawati, E., Harmoko, D. D., Rahmah, N. A., \& Dewi, N.-. (2020). Increasing English Speaking Skills Using Youtube. Polyglot: Jurnal Ilmiah, 16(1), 1. https://doi.org/10.19166/pji.v16i1.1954

Nartiningrum, N. (n.d.). Online Learning amidst Global Pandemic: EFL Students ' Challenges, Suggestions, and Needed Materials. 4(2), 115-140.

Pandiya. 2013. Rubrics on Scoring English Tests for Four Language Skills,

vol 13.http://www.polines.ac.id/ragam/index_files/jurnalr agam/ppr5\%20apr13.pdf. Accessed16 agustus 2015.

Riswandi, D. (2016). Use of YouTube-Based Videos to Improve Students' Speaking Skill. Proceeding The 2nd International Conference On Teacher Training and Education, 2(1), 269. https://jurnal.uns.ac.id/ictte/article/view/8150

Rizky Setiawan, M., \& Wiedarti, P. (2020). The effectiveness of quizlet application towards students' motivation in learning vocabulary. Studies in English Language and Education, 7(1), 83-95. https://doi.org/10.24815/siele.v7i1.15359
Sayuri, S. (2016). Problems in Speaking Faced By EFL Students of Mulawarman University. Indonesian Journal of EFL and Linguistics, 1(1), 47-61. https://doi.org/10.21462/ijefll.v1i1.4

Swari, U. R. (2020). Teaching Speaking with Gossiping in the Period of Pandemic. 182-190.

Thornbury, Scott, (2005). How to Teach Speaking, New York: Pearson Education Limited.

Tristiana1, R., \& P. Swondo, A. (2020). the Effect of Youtube Content Making on Students' Speaking Skill. Jurnal FISK, 1 No 1(1), 148-157.

Wael Abdulrahaman, A. (2016). The effective use of youtube videos for teaching English. International Journal of English Language and Linguistics Research, 4(3), 32-47. http://www.eajournals.org/wp-content/uploads/TheEffective-Use-of-Youtube-Videos-for-TeachingEnglish-Language-in-Classrooms-as-SupplementaryMaterial-at-Taibah-University-in-Alula.pdf 